\title{
Direct estimation of life expectancy in the Islamic Republic of Iran in 2003
}

F. Pourmalek, ${ }^{1}$ F. Abolhassani, ${ }^{2}$ M. Naghavi, ${ }^{3}$ K. Mohammad,${ }^{1}$ R. Majdzadeh, ${ }^{1}$ K. Holakouie Naeini ${ }^{1}$ and $A$. Fotouhi ${ }^{1}$

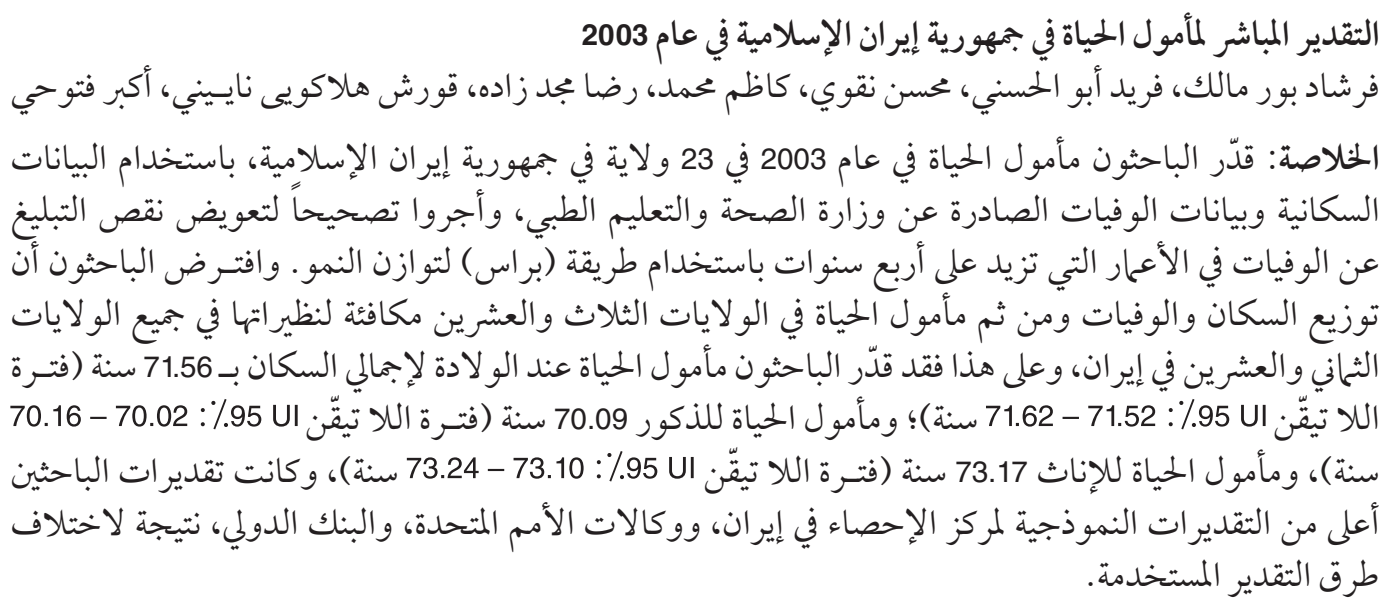

ABSTRACT We estimated the life expectancy for 2003 for 23 provinces in the Islamic Republic of Iran using population and mortality data from the Ministry of Health and Medical Education. The underreporting of deaths above 4 years was corrected using the Brass Growth Balance method. We assumed that the distributions of population, deaths, and hence life expectancy in the 23 provinces were equal to those for all 28 provinces of the country. Thus we estimated life expectancy at birth to be 71.56 years for the total population [95\% uncertainty interval (UI): 71.52-71.62]; 70.09 (95\% UI: 70.02-70.16) years for males, and 73.17 (95\% UI: 73.10-73.24) years for females. Our estimates were higher than the model-based estimates of the Statistical Centre of Iran, United Nations agencies and the World Bank, due to differences in the estimation methods used.

\section{Estimation directe de l'espérance de vie en République islamique d'Iran en 2003}

RÉSUMÉ Nous avons estimé l'espérance de vie pour 2003 dans 23 provinces de République islamique d'Iran à partir des données démographiques et des données sur la mortalité provenant du ministère de la Santé et de l'Enseignement médical. La sous-notification des décès au-delà de quatre ans a été corrigée à l'aide de la méthode d'équilibre de l'accroissement de Brass. Nous sommes partis du principe que la répartition de la population, de la mortalité et par conséquent de l'espérance de vie dans les 23 provinces était la même que dans les 28 provinces du pays. Nous avons ainsi estimé l'espérance de vie à la naissance à 71,56 ans pour l'ensemble de la population [intervalle d'incertitude (II) à $95 \%: 71,52-71,62$ ] ; 70,09 (II $95 \%$ : 70,02-70,16) pour les hommes, et 73,17 (II $95 \%: 73,10-73,24$ ) ans pour les femmes. Nos estimations étaient plus élevées que les estimations fondées sur des modèles du Centre des statistiques d'Iran, des agences des Nations Unies et de la Banque mondiale, en raison des différences entre les méthodes d'estimation utilisées.

\footnotetext{
${ }^{1}$ Epidemiology and Biostatistics Department, School of Public Health; ${ }^{2}$ Internal Diseases Department, School of Medicine, Tehran University of Medical Sciences, Islamic Republic of Iran (Correspondence to F. Pourmalek: pourmalek_farshad@yahoo.com).

${ }^{3}$ Center for Health Network Development, Ministry of Health and Medical Education, Tehran, Islamic Republic of Iran.
}

Received: 06/01/06; accepted: 18/01/07

المجلة الصحية لشرق المتوسط، منظمة الصحة العالمية، المجلد الخامس عشر، العدد (، 9 ·. 


\section{Introduction}

Life expectancy is a summary measure of health expectancy that abstracts the nonfatal outcomes of diseases and injuries in the form of a single number, i.e. life expectancy at birth, and for all age and sex groups of the population as a life table [1]. Construction of life tables and calculation of life expectancy can be done by direct and indirect methods. In the direct method, the population and mortality data measured through census and death registration systems or cross-sectional surveys are used for estimation of age- and sex-specific mortality rates and construction of life tables. With indirect methods, where directly measured population and mortality data are not used, statistical models are used instead for the estimation of specific mortality rates and the construction of life tables. The statistical model used by the World Health Organization (WHO) is the modified Brass Logit model [1]. Examples of indirect methods include global studies for estimation of life expectancy for every country of the world (by United Nations agencies) or for forecasting life expectancy in a country for future years (like the study of the Statistical Centre of Iran on life expectancy till the year 2021) [2].

Estimation of life expectancy for the population of the Islamic Republic of Iran has been done in the past in both national and international studies. For example, life expectancy at birth [ $\operatorname{LE}(0)]$ was estimated by direct method as 55.1 years for males and 56.3 years for females in 1973 in a sample survey by the School of Public Health of Tehran University [3]. In the third evaluation of Health For All-2000 in the country, the Ministry of Health and Medical Education $(\mathrm{MOH})$ estimated $\mathrm{LE}(0)$ as 68 years for males and 70 years for females in 1996 [4]. Values of $\operatorname{LE}(0)$ estimated by Unit- ed Nations agencies, the World Bank and the Statistical Centre of Iran for the years 2002-2004 are shown in Table 1.

The aim of our study was to estimate the life expectancy with a direct method using the national population and death data. At the time of performing this study, the mortality data for 23 provinces of the Islamic Republic of Iran by age group and sex for 2003 were completely available, but the coverage of the $\mathrm{MOH}$ death registration system did not include all 28 provinces of the country. Therefore 2003 was the most recent year for which the estimation of life expectancy was feasible based on data from the death registration system of $\mathrm{MOH}$, and this was selected as the reference year for our calculations.

\section{Methods}

For calculation of an abridged period life table of 23 provinces of the Islamic Republic of Iran in 2003, the number of deaths registered by $\mathrm{MOH}$ in these 23 provinces were used [14]. Under-reporting of deaths in under 5-year-olds was estimated and corrected with the Brass Growth Balance method [15]. For mortality rates of children under 1 year and 1-4 years, rates from the Demographic and Health Survey (DHS) 2000 with live births as the denominator were substituted [19]. For the total population of the 23 provinces, data were obtained from $\mathrm{MOH}$ [14]. The distribution of the population was assumed to be similar to that from DHS 2000 results, and also as result of graduation of the whole country population from 1996 census to 2003. Life expectancy was estimated by age and sex for the obtained population and corrected deaths. Calculations were made according to the methods given in the WHO national burden of disease manual with categorization into

المجلة الصحية لشرق المتوسط، منظمة الصحة العالمية، المجلد الخامس عشر، العدد (، 9 +. 


\begin{tabular}{|c|c|c|c|c|}
\hline \multirow[t]{3}{*}{ Year } & \multicolumn{3}{|c|}{ Life expectancy at birth (years) } & \multirow[t]{3}{*}{ Source } \\
\hline & Total & Males & Females & \\
\hline & PE (UI) & PE (UI) & PE (UI) & \\
\hline \multirow[t]{5}{*}{2002} & 70.32 & 68.06 & 72.69 & $\mathrm{SCl}, 2005$ [2] \\
\hline & 68.9 & $66.5(65.4-67.8)$ & $71.7(70.5-72.8)$ & WHO, 2004 [5] \\
\hline & NP & 69.0 & 71.0 & ESCAP, 2005 [6] \\
\hline & 70.1 & 68.8 & 71.7 & UNDP, 2004 [7] \\
\hline & 70.25 & 68.83 & 71.74 & World Bank, 2006 [8] \\
\hline \multirow[t]{5}{*}{2003} & 70.77 & 68.50 & 73.16 & SCI, 2005 [2] \\
\hline & $69(69-70)$ & $67(66-68)$ & $72(71-73)$ & WHO, 2005 [9] \\
\hline & NP & 68.0 & 70.0 & ESCAP, 2005 [6] \\
\hline & 70.4 & 69.0 & 71.9 & UNDP, 2005 [10] \\
\hline & 70.54 & 69.08 & 72.08 & World Bank, 2006 [8] \\
\hline \multirow[t]{4}{*}{2004} & 71.22 & 68.94 & 73.62 & $\mathrm{SCl}, 2005$ [2] \\
\hline & $70(69-71)$ & $68(66-69)$ & $72(71-73)$ & WHO, 2006 [11] \\
\hline & NP & 69.0 & 72.0 & ESCAP, 2004 [12] \\
\hline & 70.84 & 69.33 & 72.42 & World Bank, 2006 [8] \\
\hline 00-05 & 70.2 & 68.8 & 71.7 & United Nations, 2005 [13] \\
\hline
\end{tabular}

$P E=$ point estimate; $U I=$ uncertainty interval; $N P=$ not published.

$S C I=$ Statistical Centre of Iran; WHO = World Health Organization; ESCAP = United Nations Economic and Social Commission for Asia and the Pacific; UNDP = United Nations Development Programme.

19 age groups, the oldest being 85 years and above [15]. It was assumed that the distributions of the population and deaths in the 23 provinces were similar to those of the 28 provinces of the Islamic Republic of Iran in 2003 and hence the estimated life expectancy for the 23 provinces would be the same for all 28 provinces of the country.

To assess the sensitivity of the life expectancy estimation if applied to a population distribution similar to the DHS 2000 results, life expectancy was also estimated with the population distribution of the 1996 census as an alternative after graduation of the population. Graduation in 1-year age groups from the 1996 census to 2003 was done using the number of births by sex and year (from the Civil Registration Organization, with correction for delayed registration) and the number of deaths by sex, age group and year (from the vital horoscope of $\mathrm{MOH}$ for the main villages in the country).

For estimation of uncertainty limits, the Monte Carlo method with 1000 simulations for Poisson distribution of registered deaths in each of the age and sex groups was used. The 2.5 and 97.5 percentiles from obtained distributions of life expectancy in each of the age groups were identified as the $95 \%$ uncertainty interval (UI) [16]. All calculations were performed by directly writing the formulas of life table functions in Excel 
spread sheets. Add-ins for Excel [17] were used for estimation of uncertainty intervals.

\section{Results}

The population of the 23 provinces of the Islamic Republic of Iran in 2003 was 48379502 persons [14]. The same population estimated by the Statistical Center of Iran was 48.32 million [18]; the latter being about $0.12 \%$ lower than the former. The population of the 23 provinces in 2003 was $73 \%$ of the total population of the country in the same year (66.5 million). The crude mortality rate for the 23 provinces was 441 per 100000 total population, 516 for males, 363 for females [14]. The uncorrected number of deaths registered in the 23 provinces was 213000 (127000 for males, 86000 for females). Mortality rates for children under 1 year and $1-4$ years were 28.61 and 1.87 per 1000 live births respectively [19]. For the total population, the average partial death rate for the 6 age groups between 5 and 34 years (X1) was 0.0066 and the average partial birth rate of these groups (Y1) was 0.0361. The average partial death rate for the 6 age groups between 40 and 69 years (X2) was 0.0264 and average partial birth rate for these groups (Y2) was 0.0592 . Therefore the $\mathrm{K}$ correction coefficient for deaths registered for the total population in the 23 provinces was 1.17 , and the registration completeness proportion was 0.85 . With $\mathrm{K}$ correction coefficients of 1.11 and 1.25 for males and females respectively, the registration completeness proportions were 0.90 and 0.79 . Table 2 shows the correction for the under-reporting of deaths in the over 4 years age group for the 23 provinces of the coun-

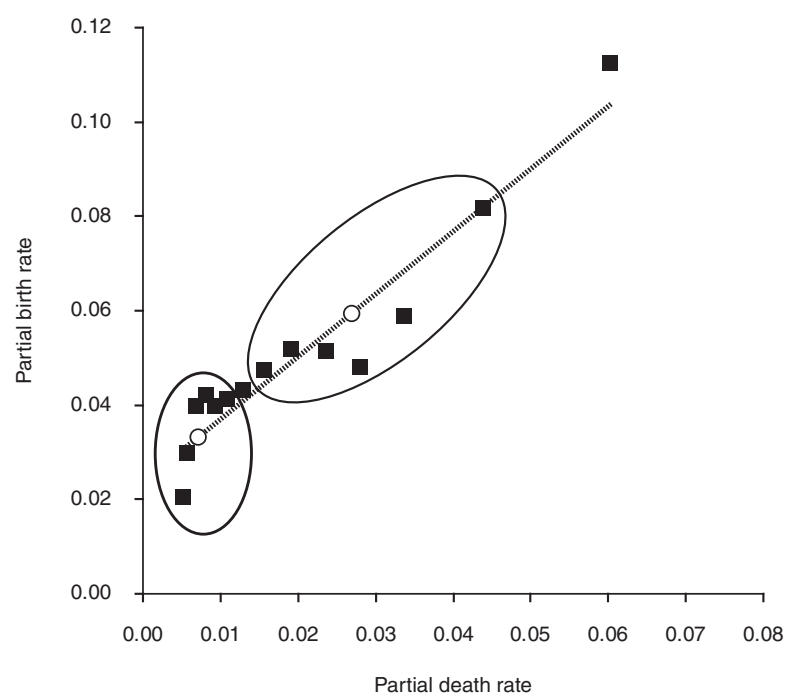

Figure 1 Plot of partial birth rates against partial death rates for the population of the 23 provinces in 2003 using Brass Growth Balance [15] for correction for under-reporting of above-4 mortality.

The 6 points in the smaller oval show partial rates of the first group (5-34 years) and 6 points in larger oval show partial rates of the second group (40-64 years). White points show the group means. Source of population data: Ministry of Health and Population [14]; source of death data: National Death Registration System [14]. 


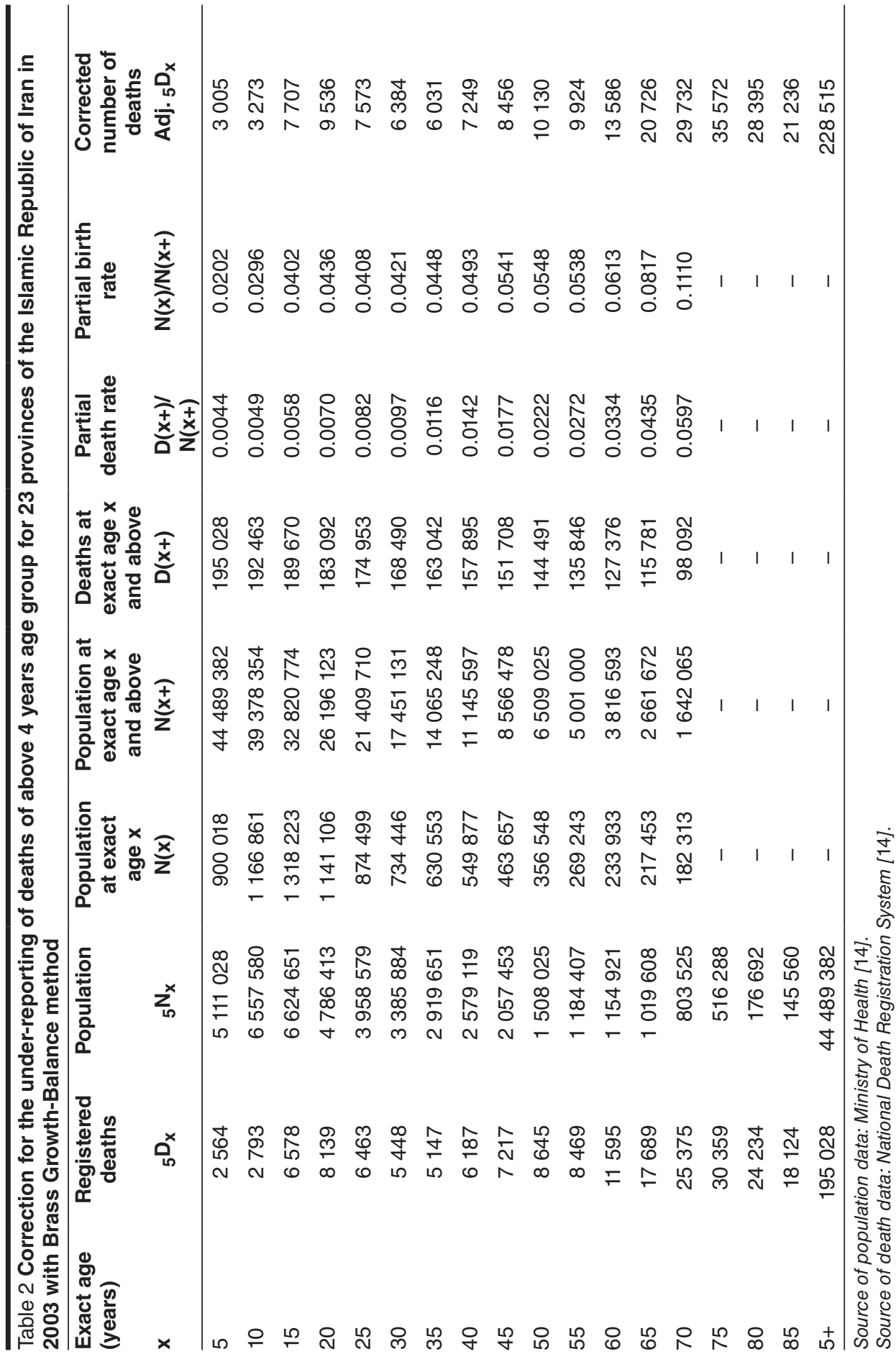

المجلة الصحية لشرق المتوسط، منظمة الصحة العالمية، المجلد الخامس عشر، العدد (، 9 ·. 
try in 2003 using the Brass Growth Balance method [15]. The plot for partial birth rates against partial death rates for the population of the 23 provinces in 2003 using the Brass Growth Balance method [15] is shown in Figure 1.

Table 3 shows the point estimates and 95\% uncertainty intervals (UI) of life expectancy for the Islamic Republic of Iran in 2003 by age and sex. Life expectancy at birth was 71.56 years for the total population (95\% UI: 71.52-71.62), 70.09 years for males (95\% UI: 70.02-70.16), and 73.17 years for females (95\% UI: 73.10 73.24). Life expectancy at birth for the total population based on the population distribution graduated from the 1996 census was 71.26 years, which is 0.3 years or $0.4 \%$ lower than the main finding of 71.56 years.

\section{Discussion}

The main finding of this study was the estimate of 71.56 years life expectancy at

Table 3 Direct point estimate and $95 \%$ uncertainty intervals of life expectancy in the Islamic Republic of Iran for 2003, by age group and sex

\begin{tabular}{lccccccccc}
\hline $\begin{array}{l}\text { Age group } \\
\text { (years) }\end{array}$ & \multicolumn{3}{c}{ Total population } & \multicolumn{3}{c}{ Males } & \multicolumn{3}{c}{ Females } \\
\hline 0 & PE & LUL & UUL & PE & LUL & UUL & PE & LUL & UUL \\
\hline $1-4$ & 71.56 & 71.52 & 71.62 & 70.09 & 70.02 & 70.16 & 73.17 & 73.10 & 73.24 \\
$5-9$ & 72.62 & 72.57 & 72.66 & 71.39 & 71.33 & 71.45 & 73.96 & 73.88 & 74.02 \\
$10-14$ & 69.15 & 69.10 & 69.19 & 67.71 & 67.65 & 67.77 & 70.71 & 70.64 & 70.77 \\
$15-19$ & 64.34 & 64.30 & 64.39 & 62.92 & 62.86 & 62.98 & 65.89 & 65.82 & 65.95 \\
$20-24$ & 59.50 & 59.45 & 59.54 & 58.08 & 58.02 & 58.14 & 61.03 & 60.96 & 61.09 \\
$25-29$ & 54.83 & 54.79 & 54.87 & 53.51 & 53.45 & 53.57 & 56.25 & 56.18 & 56.31 \\
$30-34$ & 50.36 & 50.31 & 50.40 & 49.25 & 49.19 & 49.31 & 51.53 & 51.46 & 51.59 \\
$35-39$ & 45.82 & 45.77 & 45.86 & 44.87 & 44.82 & 44.93 & 46.78 & 46.71 & 46.84 \\
$40-44$ & 41.23 & 41.19 & 41.27 & 40.44 & 40.39 & 40.50 & 42.00 & 41.93 & 42.06 \\
$45-49$ & 36.63 & 36.59 & 36.67 & 35.97 & 35.92 & 36.03 & 37.25 & 37.18 & 37.31 \\
$50-54$ & 32.11 & 32.07 & 32.15 & 31.61 & 31.56 & 31.66 & 32.55 & 32.49 & 32.61 \\
$55-59$ & 27.73 & 27.69 & 27.77 & 27.38 & 27.33 & 27.43 & 27.97 & 27.91 & 28.03 \\
$60-64$ & 23.59 & 23.55 & 23.63 & 23.46 & 23.42 & 23.51 & 23.61 & 23.55 & 23.67 \\
$65-69$ & 19.49 & 19.46 & 19.53 & 19.45 & 19.40 & 19.50 & 19.41 & 19.35 & 19.47 \\
$70-74$ & 15.52 & 15.49 & 15.56 & 15.46 & 15.41 & 15.50 & 15.45 & 15.39 & 15.51 \\
$75-79$ & 11.92 & 11.88 & 11.96 & 11.83 & 11.78 & 11.88 & 11.85 & 11.79 & 11.90 \\
$80-84$ & 8.84 & 8.80 & 8.88 & 8.66 & 8.61 & 8.71 & 8.84 & 8.77 & 8.91 \\
$85+$ & 6.49 & 6.44 & 6.54 & 6.04 & 5.98 & 6.10 & 6.71 & 6.64 & 6.80 \\
\hline
\end{tabular}

Mortality data were corrected with Brass Growth Balance method [15]; under-5 mortality was corrected with DHS 2000 results [19].

Source of population data: Ministry of Health [14]; Source of death data: National Death Registration System [14]. $P E=$ point estimate; $L U L=$ lower $95 \%$ uncertainty interval; UUL = upper $95 \%$ uncertainty interval. 
birth for the total population of the Islamic Republic of Iran in 2003, 70.09 years for males, and 73.17 years for females. The accuracy of the results depends on the degree to which the following 4 assumptions hold true.

Assumptions about the population:

i) Population distribution taken from the DHS 2000 study is reliable for the 23 provinces in the year 2003 .

ii) Population information from $\mathrm{MOH}$ for the 23 provinces in the year 2003 has adequate accuracy.

Assumptions about mortality:

iii) Death registration from $\mathrm{MOH}$ for the 23 provinces in the year 2003 has adequate coverage.

iv) Age and sex specific mortality rates in the 23 provinces in the year 2003 are generalizable to the total country in the same year.

Regarding the first assumption, the DHS 2000 study population distribution was based on direct sampling and therefore should be more accurate than similar model-based estimates as alternatives. Analysis of the sensitivity of the main finding to the use of the DHS 2000 study population distribution shows that if the population distribution graduated from the 1996 census is used as an alternative, life expectancy at birth would drop by only $0.5 \%$. Therefore the main results are negligibly sensitive to this assumption.

Regarding the second assumption, comparison of the population size for the 23 provinces from $\mathrm{MOH}$ information and the estimate of this population size by the Statistical Centre of Iran shows that the difference is about $0.1 \%$ and indicates that the accuracy of the population information from $\mathrm{MOH}$ is adequate.

Regarding the third assumption, the results of the Brass Growth Balance method show that the death registry has acceptable completeness [15]. Regarding the fourth assumption, it should be noted that among the 23 provinces, mortality rates of the 5 provinces which have the highest rates are not very different from those in the 5 provinces which have the lowest rates. Therefore it is expected that the mortality rates of the other 5 provinces (not fully covered by the death registry in 2003) should not be much different from those of the 23 provinces. Moreover, these 5 provinces have a mixture of higher, medium and lower relative development levels and their overall mortality rates (and also death registration completeness) can be comparable with mortality rates for the 23 provinces and the total country.

Increase in life expectancy from its at-birth value to year-one value is seen when the ratio of under- 1 mortality to $1-4$ years mortality is relatively high. Such an increase was also seen in the life table estimated by the School of Public Health of Tehran University in 1973 [3], and by WHO for the years 1999 [20], 2000 and 2001 [21]. Greater life expectancy for females than for males is also an expected result $[1,22]$.

Our estimates are greater than similar estimates by United Nations agencies and other international institutions, which were performed with indirect modelling methods. For the total population, the greatest difference is with WHO's estimate (2.5 years), and the least difference is with the World Bank's estimate (1 year). The estimates of these agencies and institutions differ from each other with a range of more than 1.5 years. Our estimate is only about 0.8 years lower than the estimate of the Statistical Centre of Iran, which was performed using the logistic model. Whereas population and mortality data were used for direct estimation of mortality rates and construction of a life table in our study, the UN agencies, international institutions and 
the Statistical Centre of Iran used indirect methods based on statistical modelling. Even using the various indirect methods, results are not always equal. Despite the most vigorous efforts to utilize the best input data and methods, because of differences in data and methods used by national and international organizations, all the results for the same estimations cannot be identical. It is also worth noting that in the third evaluation of Health For All 2000 in the Islamic Republic Iran, $\mathrm{MOH}$ estimated the life expectancy at birth as 68 years for males and 70 years for females in the year 1996 [4], which is 1.2 years higher than the estimate by the United Nations Economic and Social Commission for Asia and the Pacific for the same year [6], and even 1.7 years higher than the WHO estimate for 1999 [23]. Hence a similar difference between the results of direct and indirect methods was also observed for 1996 [3]. A similar difference also exists for the 1973 estimates. A small part of these differences is due to a 2.63 month $(0.22$ year $)$ difference in the Gregorian and Iranian calendars.

In the present study, the uncertainty interval was much smaller than that from studies that used indirect methods. In the direct estimation method, the only major source of variance of life expectancy is the variance of death numbers in each age group, which results in low variance of life expectancy in different ages. This is because the number of deaths is relatively high and, whether with Poisson distribution or normal distribution, this results in low variances. In model-based methods, however, there are more sources for random error of estimation. In our study the uncertainty interval was greater in older age groups (especially in the last 2 age groups), and it was also greater for each sex separately as compared with the total population (both sexes), due to fewer number of deaths, which thus resulted in greater variance.

Our direct estimate of life expectancy for the Islamic Republic of Iran in the year 2003 is 0.8 years more than the model-based estimate by the Statistical Centre of Iran and 1 to 2.5 years more than a similar estimate by United Nations agencies; this is due to differences in methods used for estimation of age and sex specific mortality rates. Direct estimates of life expectancy by the Ministry of Health for 1996 and by the School of Public Health of Tehran University for 1973 had a similar difference with estimates by Statistical Centre of Iran and United Nations agencies for the same reason.

\section{References}

1. Murray CJL, Evans DB. Health systems performance assessment: debates, methods and empiricism. Geneva, World Health Organization, 2003.

2. Statistical Centre of Iran. 2005. [Child mortality trends and indicators in Iran in years 1335-1400 (1956-2021)]. (http://amar.sci. org.ir/index_e.aspx, accessed 7 August 2008) [in Farsi].

3. Nehapetian V, Khazaneh H. [Life indicators of Iran: mortality, fertility, population growth, life table.] Tehran, School of Public Health and School of Public Health of Tehran University, 1978:186 (Serial No. 1992) [in Farsi].

4. Mohammad K, Malekafzali H, Nehapetian V. [Statistical methods and health indices, 9th ed.]. Tehran, Mohammad K, Malekafzali H, Nehapetian V, 1998:283 [in Farsi].

5. World health report 2004 - changing history. Geneva, World Health Organization, 2004:114-5. 
6. Statistical Yearbook for Asia and the Pacific, 2004. Bangkok, United Nations Economic and Social Commission for Asia and the Pacific, 2005:184.

7. Human Development Report 2004: cultural liberty in today's diverse world. New York, United Nations Development Programme, 2004:141 \& 219 .

8. World Bank. World Development Indicators Database (http://devdata.worldbank. org/query/, accessed 7 August 2008).

9. World health report 2005: make every mother and child count. Geneva, World Health Organization, 2005:176-7.

10. Human Development Report 2005: a better investment climate for everyone. New York, United Nations Development Programme, 2005:220.

11. World Health Report 2006: working together for health. Geneva. World Health Organization, 2006:170-1.

12. United Nations Economic and Social Commission for Asia and the Pacific. Statistical indicators for Asia and the Pacific: 2006 (http://www.unescap.org/stat/data/statind/ index.asp, http://www.unescap.org/stat/, accessed 7 August 2008).

13. United Nations. World population prospects, 2005 (http://esa.un.org/unpp accessed 7 August 2008).

14. Naghavi M. [Profile of death in 23 provinces of Iran in year 1382 (2003)]. Tehran, Center for Health Network Expansion and Health Promotion, Health Deputy, Ministry of Health and Medical Education, 2005 [in Farsi].

15. National burden of disease studies: a practical guide. Geneva, World Health Organization, Global Programme on Evidence for Health Policy, 2001:26.
16. Salomon JA et al. Methods for life expectancy and healthy life expectancy uncertainty analysis. Geneva, World Health Organization, Global Programme on Evidence for Health Policy, 2001 (Working Paper No. 10).

17. @ Risk version 4.5.3. Newfield, Palisade Corporation, 2004 (Standard edition. Trial version).

18. [Reconstruction and estimation of urban population of Iran based on year 1380 (2001) limits]. Tehran, Statistical Center of Iran, 2004 [in Farsi].

19. Population and health in the Islamic Republic of Iran: Iran Demographic and Health Survey (DHS) 2000. Tehran, Ministry of Health and Medical Education, 2000.

20. Lopez AD et al. Life tables for 191 countries: Data, methods and results. Geneva, World Health Organization, 2002 (GPE Discussion Paper Series No. 9).

21. World Health Organization Statistical Information System (WHOSIS). Life Table of the Islamic Republic of Iran in2000 and 2001 (http://www3.who.int/whosis/life/ life_tables/download/life_Iran_(Islamic_ Republic_of)_2000.csv, accessed June 2005).

22. Murray CJL, Lopez AD. The global burden of disease: a comprehensive assessment of mortality and disability from diseases, injuries, and risk factors in 1990 and projected to 2020. Cambridge, Harvard School of Public Health on behalf of the World Health Organization and the World Bank, 1996.

23. World Health Report 2000. Health systems: improving performance. Geneva, World Health Organization, 2000:159. 